\title{
MEDIATED COMMUNICATION AND DEPENDENCE BEHAVIORAL ACTIVITY OF RACCOON DOG (NYCTEREUTES PROCYONOIDES GRAY, 1834) ON WEATHER CONDITIONS
}

(C) 2016

E.S. Kamalova, postgraduate student of the Chair of Ecology, Botany and Nature Protection Samara National Research University, Samara (Russia)

Abstract. The raccoon dog is an invasive species in the Samara region. At present, this species is founded in the northern, north-western and western territories of the Samara region, and the most widely spread on Vasilyevsky Islands, near the Rozhdestveno village, in floodplain areas of the national park «Samarskaya Luka». According to some authors' data, this species may be able to be cause damage to game species, due to it's impact on the number of waterfowl. In the Samara region the impact of this predator on hunting species are not mentioned, but a comprehensive study of the behavior, distribution, ecology of the species and its impact on native ecosystems are required. This article describes a study on raccoon dog's mediated communication which was carried out by detailed method of tracking animals' winter footprints in the national park «Samarskaya Luka» in the snow season at 2009-2015. The dynamics of communicative behavior of raccoon dog at 2009-2015 is presented. One of the main factors influencing on animal's behavior is a snow cover. For the detailed analysis Bodman's index of weather rigidity was applied, using data of the air temperature and wind speed. The data which show differences in behavioral activity of raccoon dog's males and females depending on the weather conditions are presented.

Keywords: raccoon dog; Nyctereutes procyonoides; mediated communication; intraspecific communication; marking behavior; detail footprints tracking; biological signaling field; behavioral activity; elementary motor act; invasive species; adaptation; snow cover; Bodman index; Samarskaya Luka; floodplain areas.

УДК 0058 01/.07+00502.75

\section{ПРЕДВАРИТЕЛЬНЫЕ ИТОГИ МОНИТОРИНГА БИОЭКОЛОГИЧЕСКИХ ОСОБЕННОСТЕЙ РАСТЕНИЙ РЯБЧИКА РУССКОГО (FRITILLARIA RUTHENICA WIKSTR.) В МОДЕЛЬНЫХ БИОТОПАХ КРАСНОСАМАРСКОГО ЛЕСНИЧЕСТВА} (C) 2016

М.Г. Котельникова, аспирант кафедры экологии, ботаники и охраны природы Самарский национальный исследовательский университет имени академика С.П. Королёва, Самара (Россия)

Aннотация. В статье представлены предварительные итоги мониторинга растений рябчика русского (Fritillaria ruthenica Wikstr.), относящегося к категории редких и исчезающих видов растений, включенного в Красную Книгу России и Самарской области. Путем обобщения доступных источников нами составлена общая характеристика морфологических и биоэкологических особенностей растения. В 2012-2014 гг. было проведено исследование рябчика в Красносамарском лесничестве, полученные данные использовали для установления морфометрических показателей растений рябчика русского, оценки уровня их изменчивости и сопоставления с указанными в литературе для данного растения количественными признаками. Было установлено, что длина побегов у растений рябчика русского в обследованном модельном биотопе Красносамарского леса в 2012 2014 гг. изменялась в интервале 20 .. 70 см, в 2012 и 2013 гг. преобладали особи с длиной побега около 50 см, в 2014 г. - около 50 и 60 см. Признак длины побега характеризуется пластичностью, наибольший уровень варьирования отмечен в 2013 г. Значения длины побегов вписываются в диапазон, указанный для различных частей ареала в литературе, при значительной доле «высоких» растений в обследованной популяции. Это может свидетельствовать о благоприятности условий произрастания и возможности сохранения в составе растительных сообществ при отсутствии лимитирующих антропогенных факторов.

Ключевые слова: Fritillaria ruthenica Wikstr; морфологические и биоэкологические особенности; количественные и качественные характеристики; длина побега; Красносамарское лесничество; модельный биотоп; Самарская область.

Самарская (Куйбышевская) область относится к числу интереснейших регионов Восточно-Европейской равнины. На территории данной равнины было несколько оледенений, но ни одно из них не затронуло Самарскую область, что позволило сохранить до наших дней популяции многих реликтовых растений, во флоре области представлены эндемичные виды различного статуса. Долговременные изменения природных условий стали причиной сокращения лесистости и развития степных пространств, влияние человека в последние эпохи ускорило сокращение лесопокрытых территорий и еще сильнее - степей, ко- торые подверглись распашке. В современных условиях в районах Самарской области на долю агроэкосистем приходится от 50 до 90\%, сохранившиеся фрагменты природных экосистем подвергаются сильному антропогенному воздействию [1]. На данный момент во флоре области насчитывается 258 редких и исчезающих видов растений [2], в этих условиях изучение биологических особенностей редких растений приобретает особую важность для их сохранения. Наша статья посвящена рассмотрению биоэкологических особенностей рябчика русского Fritillaria ruthenica Wikstr. - редкого вида, внесенно- 
го в Красные книги РФ, Самарской области и значительного числа Красных книг других регионов России и Украины.

Детальная характеристика морфологических и биоэкологических особенностей растения, составленная нами путем сопоставления и обобщения информации ряда источников [2-30] с дополнением данными наших наблюдений, позволяет указать для исследуемого вида ведущие количественные и качественные признаки.

Общий ареал рябчика русского охватывает Восточную Европу, Кавказ, Западную Сибирь, Среднюю Азию [3]. В России он встречается в черноземных районах европейской части (северная граница распространения проходит по р. Оке) и в Западной Сибири. [7]. Ареал вида в пределах бывшего РСФСР включает юг Московской, Брянскую, восток Калужской, Тульскую, Рязанскую, Орловскую области, все области Центрального Черноземья, почти всю Ростовскую область, юг Восточно-Вятского района (Мордовская АССР и часть Горьковской области), значительную часть Поволжья (за исключением северных районов Татарской и Башкирской АССР, Астраханской области и Калмыцкой АССР), Оренбургскую, южную часть Челябинской и крайний юг Курганской областей $[13 ; 14]$. Западная граница ареала проходит по Украине: Киевская область, Кировоградская область, Криворожская область. В Нижегородской области вид был обнаружен в начале XX века в окрестностях р.п. Вад, т.е. севернее границы ареала, однако достоверных сведений о местах произрастания вида в данной области нет [10].

На территории Самарской области популяции рябчик русский произрастает небольшими группами во всех районах, особенно в западных [2]. На данный момент известны следующие местообитания рябчика русского в Самарской области, большая часть которых приурочена к различным формам ООПТ: Богатырёв и Сырой овраги, балки Вязовская, Кладовая, Барсучиха и Мурашиха, долы Каменный и Куркин, степь в окрестностях хутора Росташи, Синий Сырт, урочище Грызлы, гора Куратас-Чагы, гора Копейка, степь около с. Ойкино, окрестности д. Софьино, степные водоразделы вблизи с. Успенка, Западный Малокинельский байрачно-степной комплекс, Абдулзаводская дубрава в Похвистневском районе, Шаронов овраг в Красноярском районе, Калиновый дол и целинная сыртовая степь в Большеглушицком районе $[2 ; 4-5 ; 24-27 ; 29 ; 31]$.

Рябчик русский представляет собой луковичный травянистый многолетник, весенний эфемероидгеофит. Сроки цветения для данного вида в литературе указываются «конец апреля - май», в условиях Самарской области обычно цветение в начале мая, в отдельные годы может начинаться в последней декаде апреля и длится от недели и более (срок цветения сокращается при быстром наступлении жаркой засушливой погоды в отдельные годы). Период плодоношения в литературе для рябчика указывается «конец мая - начало июня», продолжительность вегетации - около 80 дней.

Подземная часть растения представляет собой клубнелуковицу (во многих источниках указывается как луковица), размеры которой у генеративных осо- бей составляют, по указанию большинства источников, до $1 \mathrm{~cm}$, в условиях Самарской области могут превышать данный размер. Клубнелуковица включает 2-3 мясистых чешуи, между которыми залегают почки возобновления, одна из которых дает начало генеративному побегу, другие служат для формирования дочерних луковичек-деток (вегетативного размножения растения). Ряд источников указывает для данного растения наличие 1 мясистой и 2 пленчатых чешуй в составе луковицы $[9 ; 10]$.

Размах значений высоты генеративного побега, которые указываются для данного вида в литературе, составляют 20-60 см, при этом в разных частях ареала размеры растений, по всей вероятности, варьируются. Так, длина побега у растений для Украины составляет 20-60 см, в Московской области - 20-70 см, Самарской области - 20-60 см, Сибири - 20-40 см, для республики Башкортостан указывается в пределах 15-50 см, Оренбургской области - 15-50 см, в Брянской области - до 50, в Нижегородской области - до 40 см [2; 8-17]. В ряде других источников приводятся значения: 40 см [29], 50 см [23], 50 см, согласно П.Ф. Маевскому [18], в средней полосе европейской части России длина побега варьирует в пределах 15-30 см.

Стебель прямой, тонкий, голый, с восковым налетом, в верхней части может иметь коричневатый оттенок, гладкий, начиная от второй трети олиственный. Нижние листья мутовчатые или супротивные, до 11-19 штук, слегка стеблеобъемлющие, линейные, острые, в большинстве источников указаны их размеры: длина 6-9 см, ширина 3-10 мм [8; 10-11; 22; $28 ; 30]$. Верхние листья супротивные, почти нитевидные, с тонкими спирально закрученными усиковидными цепкими верхушками. Ими рябчик цепляется за другие растений, получая дополнительную опору для удержания веса соцветий и завязавшихся плодов. Однако наблюдения за растениями рябчика в природе показывают, что использование опоры не является обязательным и в разреженном травостое стебель даже при созревании плодов сохраняет вертикальное положение.

Генеративный побег несет от 1 до 5 крупных поникающих цветков (в литературе указано максимальное количество - до 8-10 штук [23], что для данного вида, вероятно, является аномалией развития генеративного побега). Цветки находятся в пазухах верхних листьев на коротких дуговидных цветоножках и собраны в рыхлую кисть. Нами в природе в течение ряда лет наблюдалось преобладание побегов с 1-2, изредка 3 цветками.

Околоцветник колокольчатый, окраска его наружной стороны указывается разными авторами как темно-красная, бордовая, фиолетовая с более темным неясным шахматовидным (шахматным) рисунком. Изнутри околоцветник имеет желтоватую окраску с зеленоватыми полосками вдоль лепестков и на их верхушке. Наружные доли околоцветника узкоовальные, до 3 см длиной и 8 мм шириной, внутренние обратнояйцевидные, до 3,5 см длиной и до 15 мм шириной, с оттянутой тупой верхушкой [7]. Нектарники неглубокие, округло-овальные, резко выдающиеся наружу в виде бугорков. Столбик длиннее тычинок, до середины разделенный на 3 рыльца. Пыльники короче книзу расширенных нитей. 
Коробочка рябчика русского шестигранная, крылатая (узкокрылатая), сверху притупленная, книзу слабо суженная. В большинстве источников указываются следующие размеры коробочки: длина - 1,52 см, ширина - 1,5-1,8 см $[11 ; 22 ; 28 ; 30]$, однако в условиях Самарской области часто встречались плоды рябчика больших размеров.

Рябчик русский в пределах ареала произрастает в лесной и лесостепной зоне, обычен по опушкам, полянам и в зарослях степных кустарников; также отмечен на песчаных террасах и на остепненных каменистых, щебнистых и меловых склонах холмов и гор [13; 18; 24; 32], в зоне широколиственных лесов, в разнотравно-типчаковых остепненных лугах [10; 13], в остепненных дубравах, по осветленным лиственных и сосново-лиственным лесам, остепненным лесным полянам, иногда в степях [21]. Реже отмечается на солонцеватых лугах [11]. По некоторым источникам, предпочитает местоположение на незаливаемых террасах и склонах балок [7; 30]. На территории Украины отмечен в экотонах между лесной и луговостепной растительностью и в лугово-степных группировках. [16]. Раннее начало вегетации и ее сравнительно быстрое завершение позволяют рябчику русскому произрастать как в травянистых, так и в кустарниковых сообществах и на лесных опушках, не страдая от конкуренции с высокими видами травостоя и затенения кустарниками и травами. Рябчик русский светолюбив, но нормально развивается и в полутени. Диапазон освещенности - открытые и полуоткрытые пространства [8]. По некоторым данным, рябчик приурочен к хорошо прогреваемым, но затененным участкам [9].

Многие авторы отмечают [8-9; 23], что данный вид требователен к богатству почвы, нередко растет на карбонатных субстратах. Растение довольствуется влагой верхнего слоя почвы, поскольку его луковица с придаточными корнями залегает на небольшой глубине в верхнем почвенном горизонте. Для него, как и большинства луковичных растений, негативными свойствами почвенной среды оказываются тяжелый механический состав, слитное сложение, избыточное увлажнение и застой влаги. В соответствии с потребностями в увлажнении характеризуется как ксеромезофит. Раннее прекращение вегетации и переход в состояние покоя является приспособлением к перенесению засухи, по отношению к которой использует стратегию избегания [9]. В лесостепи и степи встречается преимущественно на выщелоченных черноземах, нередко растет на меловых и известковых субстратах (кальциефил) [9; 16]. По данным Самарской области, требователен к определенным эдафическим (черноземным почвам) и ценотическим (богаторазнотравные степные сообщества) условиям [2].

В некоторых источниках отмечена плотность популяций данного вида. Так, на территории Украины [15] популяции рябчика русского немногочисленны от 1 до 10 особей на $1 \mathrm{M}^{2}$ при средней площади от 0,01 до 0,02 га, от 10 до 20 особей на $1 \mathrm{~m}^{2}(0,01$ до 0,01 га). По типу пространственной структуры популяции вида они характеризуются как изолированные локальные, реже линейные, по типу возрастной структуры - полночленные, устойчивые, гомеостатические. На территории Самарской области в типич- ных местах обитания численность рябчика может быть высокой, достигая 50-100 особей на $100 \mathrm{~m}^{2}$ [2].

Источники 60-70 гг. [21] отмечают обычность растения для флоры СССР и в пределах ареала распространения, однако в настоящее время вид значительно сокращает свою численность. Уменьшение численности большинство авторов связывают с возрастанием антропогенной нагрузки на места произрастания (вырубка лесов, выпас скота, весенние пожары, распашка степей) и сбором цветов в букеты, а также с уязвимостью за границей ареала.

Вид внесен в Красную книгу РСФСР в категории 3 ® - редкий вид; эндемик флоры СССР; Красную книгу Российской Федерации (категория 3 - редкий таксон), Украины (статус - уязвимый вид) [1315].

Также отмечен в Красных книгах Самарской (категория V - восстанавливаемый в численности таксон), Ульяновской (категория $2(\mathrm{~V})$, редкий и уязвимый вид), Челябинской (III категория, редкий вид), Брянской (0-я категория - вид, по-видимому, исчез), Нижегородской (категория А - вид, находящийся под угрозой исчезновения: вид, численность которого достигла критического уровня или же его места обитания претерпели столь коренные изменения, что в ближайшее время, видимо, исчезнут), Московской (2-3 категория - редкий, сокращающийся в численности вид) областей, Республики Башкортостан (3-я категория, редкий вид) [2; 8-17] и др.

Одним из мест произрастания рябчика русского является Красносамарский лес, представляющий собой крупный (около 30 тыс. га) лесной массив, расположенный в зоне разнотравно-типчаково-ковыльных степей обыкновенного чернозема. Слагают данный массив естественные дубравы, березняки, осокорники, осинники, ольшаники, ивняки, а также искусственно созданные насаждения - ельники и сосняки. К ландшафту открытых пространств (прогалины, опушки, поляны, многочисленные озера) приурочены кустарниковые, луговые, степные и рогозово-осоковые сообщества. Наряду с этим, зональным типом растительности для Красносамарского леса являются разнотравно-типчаково-ковыльные степи, занимающие значительные площади как на незаливаемых возвышенных участках поймы, так и на арене p. Самары [31-32]. Находясь в пределах зоны настоящих степей, в аридном климате крайнего юговостока европейской территории России, долиннотеррасовый ландшафт с относительно влагоемкими, преимущественно песчаными и супесчаными почвами (повышенная эвапотранспирация по сравнению с суглинистыми обыкновенными черноземами) дает приют удивительному сочетанию ксерофильных и мезофильных элементов, с одной стороны, степной, а с другой стороны - лесной и луговой флор [32-33].

С мая 1974 года сотрудниками биологического факультета Самарского государственного университета проводится мониторинг Красносамарского лесного массива. На его территории произрастает 53 вида сосудистых растений, 2 вида лишайника, внесенные в Красные книги федерального и регионального уровней. 21 вид включен в список редких и уязвимых таксонов, нуждающихся в постоянном контроле и наблюдении на территории Самарской 
области, 14 видов раритетны для Волго-Уральского региона [32-33]. В частности, на данном лесном массиве были найдены и обозначены 4 ценопопуляции рябчика русского [19]. В период 2012-2015 гг. нами было проведен мониторинг некоторых популяций рябчика, произрастающих в модельных биотопах Красносамарского лесничества.

Целью нашей работы было определение морфометрических показателей растений рябчика русского, установленных в ходе мониторинга популяций данного растения в условиях Красносамарского леса в 2012-2014 гг., оценка уровня их изменчивости и сопоставление с указанными в литературе для данного растения количественными признаками.

Методика работы. Объектом нашего исследования были выявленные в результате маршрутного обследования территории Красносамарского леса ценопопуляции рябчика русского в квартале 66 (биотоп луговой степи). Условия произрастания популяций: склон лесной дороги, 152 м над уровнем моря. Расти- тельное сообщество - луговая степь с доминированием следующих видов: ковыль перистый, подмаренник русский, полынь Маршала, ракитник русский. Почва супесчаная, выщелоченный чернозем, содержание гумуса около 4\%, pH водной вытяжки $=6,9$, в водной вытяжке отмечено содержание $\mathrm{Ca}^{2+}$ (сотые доли). Обследование популяций рябчика проводили в период завершения формирования семян (середина июля 2012, 2013 и 2014 гг.), когда побеги прекратили рост и достигли своих предельных размеров. У изучаемых экземпляров определяли показатели длины побега растений, длины и ширины коробочки.

Погода вегетационных периодов (рис. 1) обеспечила различные условия для развития растений рябчика русского, что проявилось в неодинаковом уровне увлажнения: влагообеспеченность в период с апреля по июль была благоприятной в 2012 г., непостоянной в 2014 г. и недостаточной в 2013 г. Отмечались также различия температурного уровня и быстроты наступления жаркой погоды в конце весны.

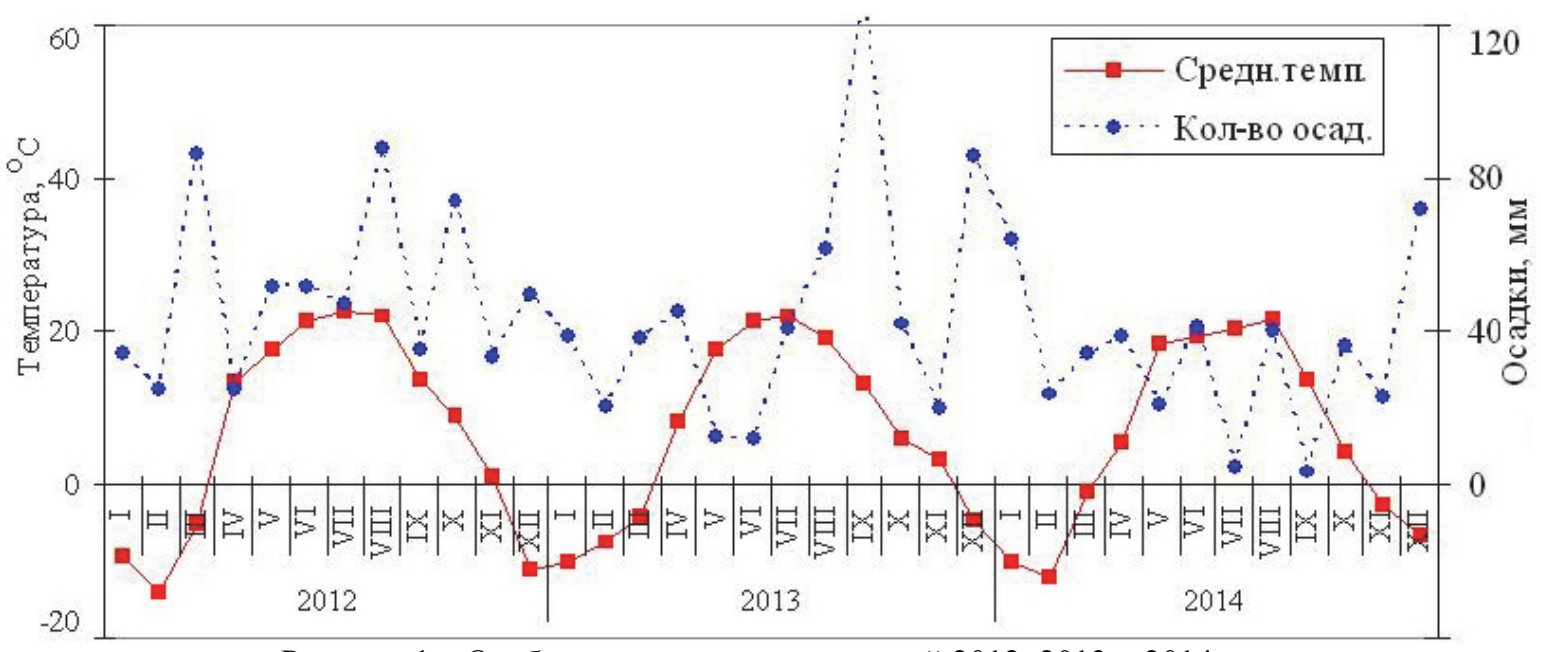

Рисунок 1 - Особенности погодных условий 2012, 2013 и 2014 гг.

Рассмотрим распределение показателя длины побега у обследованных растений рябчика русского в три описываемых сезона. Ранжирование рядов данных и построение на их основе графиков распределения (рис. 2) показало, что все сезоны длина побегов изменялась в интервале $20 \ldots 70 \mathrm{~cm}$, в 2012 г. отчетливо преобладали особи с длиной побега около 50 см, в 2013 г. наибольшее число растений имело длину побега $40 \ldots 50$ см, в 2014 г. преобладали растения с длиной побегов $50 \ldots 60 \mathrm{~cm}$.

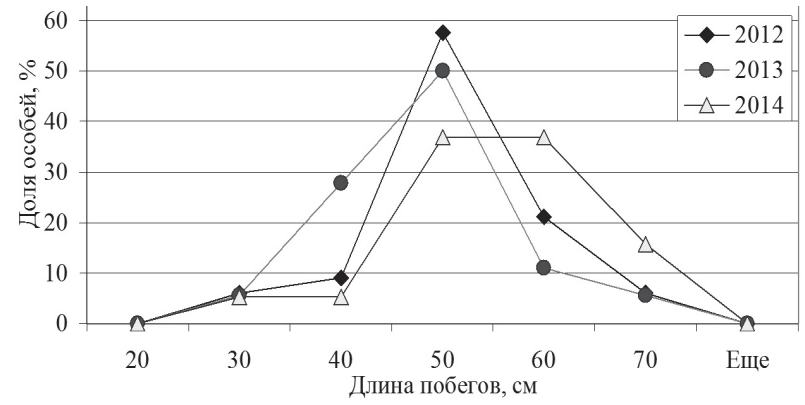

Рисунок 2 - Средняя длина побега растений рябчика русского с модельных популяций КСЛ

Эти результаты логично согласуются с описанными выше особенностями погодных условий, в которых происходило развитие растений. Повышенный тепловой режим и некоторая ограниченность увлажнения в 2014 г. способствовали формированию большей, чем в другие годы, доли растений с длиной побега 60 и 70 см при снижении доли особей с длиной побегов 50 см. Возможно, в этот год отдельные растения смогли более заметно использовать незначительные преимущества своего размещения в границах биотопа. В 2012 г. распределение растений по длине побега продемонстрировало наиболее отчетливую одновершинность, то есть развитие протекало во вполне благоприятных условиях, и значительная доля растений достигла «стандартного» показателя длины побега 50 см. В 2013 г. развившийся в начале периода вегетации дефицит влаги ограничил рост растений, что выразилось в увеличении доли растений с длиной побега 40 см. Отмеченные особенности развития растений в разные годы можно считать проявлением экологической пластичности рябчика русского, способности оперативно реагировать на комплекс погодных условий.

Сравнивая полученные для растений Красносамарского леса данные с приведенными в многочисленных источниках литературы значениями длины побегов рябчика русского, мы можем оценить их как совпадающие с указанным диапазоном значений по длине побега, при значительной доле «высоких» рас- 
тений в обследованной популяции. Это может означать благоприятность условий произрастания, а значит - возможность и далее успешно сохраняться в составе сообщества при условии отсутствия лимитирующих антропогенных факторов.

Что касается изменчивости признака длины побега, значения коэффициента вариации подтвердили заметную пластичность данного признака, что вполне согласуется с биоэкологической спецификой побега. Значения коэффициента вариации приближались к 20\% либо превышали данный уровень (рис. 3 ), причем наибольший уровень варьирования отмечен в 2013 г. Этому году соответствовали довольно засушливые условия начала летнего периода, в которых, как мы можем предположить, существенно возросло значение небольших различий точек произрастания растений по увлажнению почвы и температурному режиму.

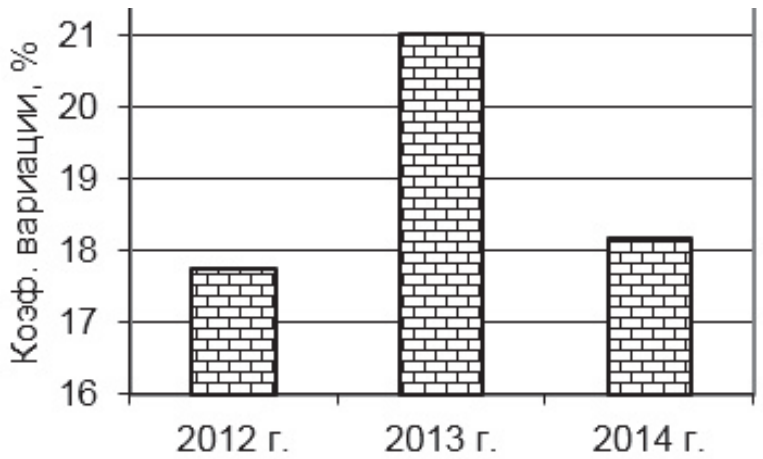

Рисунок 3 - Коэффициент вариации длины побега рябчика русского

Таким образом, длина побегов у растений рябчика русского в обследованном модельном биотопе Красносамарского леса в 2012-2014 гг. изменялась в интервале $20 \ldots 70$ см, в 2012 и 2013 гг. преобладали особи с длиной побега около 50 см, в 2014 г. - около 50 и 60 см. Признак длины побега характеризуется пластичностью, его значения вписываются в диапазон значений, указанный для различных частей ареала в литературе, при значительной доле «высоких» растений в обследованной популяции. Данный факт может свидетельствовать о благоприятности условий произрастания и возможности сохранения в составе растительных сообществ при отсутствии лимитирующих антропогенных факторов.

\section{СПИСОК ЛИТЕРАТУРЫ:}

1. Кавеленова Л.М., Прохорова Н.В., Головлев А.А., Розно С.А. Сохранение фиторазнообразия как составная часть стратегии устойчивого развития Самарской области // Поволжский экологический журнал. 2014. № 1. С. 12-20.

2. Красная книга Самарской области. Т. 1. Редкие виды растений, лишайников и грибов / под ред. чл.корр. РАН Г.С. Розенберга и проф. С.В. Саксонова. Тольятти: ИЭВБ РАН, 2003. С. 154.

3. Артюшенко Э.Т. Род 16. Рябчик - Fritillaria L. // Флора европейской части СССР. Л.: Наука, Ленингр. отд-ние, 1979. Т. 4. С. 238-243.

4. Головлев А.А., Прохорова Н.В. Природа Самарской области (краснокнижные растения и животные, их охрана, биологические ресурсы): учеб. пособие. Ульяновск: Вектор-С, 2008. С. 110-111.
5. Горелов М.С., Матвеев В.И., Устинова А.А Природа Куйбышевской области. Куйбышев: Кн. изд-во, 1990. С. 254-255.

6. Зеленая книга Поволжья: Охраняемые природные территории Самарской области. Самара: Кн. издво, 1995. С. 150-200.

7. Иллюстрированный определитель растений Средней России. Т. 1. Папоротники, хвощи, плауны, голосеменные, покрытосеменные (однодольные) / И.А. Губанов, К.В. Киселёва, В.С. Новиков, В.Н. Тихомиров. М.: Т-во научных изданий КМК, Ин-т технологических исследований, 2003. С. 458.

8 Красная книга Брянской области. Растения. Грибы / О.И. Евстигнеев и др.; отв. ред. Ю.П. Федотов. Брянск: Читай-Город, 2004. 271 с.

9. Красная книга Московской области (издание второе, дополненное и переработанное) / Отв. ред.: Т.И. Варлыгина, В.А. Зубакин, Н.А. Соболев. М.: Товарищество научных изданий КМК, 2008. 828 с.

10. Красная книга Нижегородской области. Т. 2. Сосудистые растения, водоросли, лишайники, грибы. Нижний Новгород, 2005. 328 с.

11. Красная книга Республики Башкортостан (объединенный том) / под ред. А.А. Фаухутдинова. Уфа: Полипак, 2007. С. 72

12. Красная книга Республики Татарстан. Казань: Животные, растения, грибы. Казань: Идел-Пресс, 2006. 232 c.

13. Красная книга Российской Федерации (растения и грибы) / гл. редкол.: Ю.П. Трутнев и др.; сост. Р.В. Камелин и др. М.: Товарищество научных изданий КМК, 2008. 885 с.

14. Красная книга РСФСР (растения). М.: Росагропроиздат, 1988. С. 259.

15. Красная книга Украины / под ред. И.К. Акимова. Киев: Глобалконсалтинг, 2009. 912 с.

16. Красная книга Ульяновской области (растения): в 2 т. Т. 2. / под науч. ред. Н.С. Ракова; Правительство Ульяновской области. Ульяновск: УлГУ, 2005. C. $124-125$.

17. Красная книга Челябинской области: животные, растения, грибы / отв. ред. Н.С. Корытин. Екатеринбург: Изд-во Урал. ун-та, 2005. 450 с.

18. Маевский П.Ф. Флора средней полосы европейской части России. М.: Товарищество научных изданий КМК, 2006. С. 156.

19. Оценка состояния флористического фиторазнообразия особо ценного Красносамарского лесного массива в целях научного обоснования проведения мероприятий по его охране и рациональному использованию (Отчет о НИР). Самара, 2008. 214 с.

20. Рябинина 3.Н., Князев М.С. Определитель сосудистых растений Оренбургской области. М.: Товарищество научных изданий КМК, 2009. С. 152.

21. Терехов А.Ф. Определитель весенних и осенних растений Среднего Поволжья и Заволжья. Куйбышев: Куйбышевское книжное издательство, 1969. С. 395-396.

22. Травянистые растения СССР / Ю.Е. Алексеев, В.Н. Вехов, Г.П. Гапочка, Ю.К. Дундин и др. М.: Мысль, 1971. С. 294.

23. Sadovod Online [Электронный ресурс] // http:// sadovod.ru/content/book/eufritillaria.

24. Саксонов С.В. Самаролукский флористический феномен. М.: Наука, 2006. 120 с. 
25. Саксонов С.В. О видах растений, лишайников и грибов Красной книги Российской Федерации // Самарская Лука: Бюллетень. 2006. № 17. С. 253-285.

26. Соловьёва В.В., Старкова Т.С., Старков М.Н. Популяции редких охраняемых растений на склонах Шаронова оврага Красноярского района // Природное наследие России: изучение, мониторинг, охрана: Материалы Международной конф. (Тольятти, Россия, 21-24 сентября 2004 г.). Тольятти: ИЭВБ РАН, 2004. C. 256.

27. Ужамецкая Е.А. Растительные ассоциации балки Каменный дол, рекомендуемые к охране // Природное наследие России: изучение, мониторинг, охрана: Материалы Междунар. конф. (Тольятти, Россия, 21-24 сентября 2004 г.). Тольятти: ИЭВБ РАН, 2004. C. $327-328$.

28. Флора Нижнего Поволжья. Т. 1 Споровые, голосеменные, однодольные. М.: Товарищество научных изданий КМК, 2006. С. 363.

29. Флора памятника природы «Гора Зелёная» Елховского района Самарской области / С.В. Саксо- нов, А.В. Лобанова, А.И. Иванова, В.Н. Ильина и др. // Вестник Волжского университета им. В.Н. Татищева. Серия «Экология». Вып. 5. Тольятти: ВУиТ, 2005. C. 6-20.

30. Флора Сибири. Т. 4. Новосибирск: Наука, 1987. C. 101.

31. Изучение лесных экосистем степного Поволжья / Н.М. Матвеев, В.Г. Терентьев, К.Н. Филиппова, О.Е. Дёмина. Куйбышев: Куйбышевский госуниверситет, 1990. С. 48.

32. Флористическое разнообразие особо ценного Красносамарского лесного массива Самарской области: I. Сосудистые растения // Самарская Лука: проблемы региональной и глобальной экологии. 2010. T. 19, № 1. C. 111-136.

33. Матвеев Н.М., Филиппова К.Н., Дёмина О.Е. Систематический и экоморфный анализ флоры Красносамарского лесного массива в зоне настоящих степей // Вопросы экологии и охраны природы в лесостепной и степной зонах: Межв. сб. науч. тр. Самара: Самарский университет, 1995. С. 41-71.

\section{PRELIMINARY RESULTS OF THE MONITORING BIO-ECOLOGICAL FEATURES OF PLANTS FRITILLARIA RUTHENICA WIKSTR. IN THE MODEL FOREST HABITATS OF THE KRASNOSAMARSKY FOREST}

(C) 2016

\section{M.G. Kotelnikova, postgraduate student of the Chair of Ecology, Botany and Nature Protection} Samara National Research University, Samara (Russia)

Abstract. The article presents some preliminary results of the monitoring of Fritillaria ruthenica Wikstr. plants (category of rare and endangered plant species, included in the Red Books of Russia and Samara Region). By summarizing the available sources of science literature we have compiled a general description of morphological and bioecological species characteristics. The results of the field study fulfilled in 2012-2014 in Krasnosamarsky forestry (Samara region) were used to determine morphometric parameters of Fritillaria ruthenica plants. The data also helped us to assess the variability level and to make a comparison with plant quantitative traits given in the literature. It was found that the shoot length of Fritillaria ruthenica plants from model biotope in Krasnosamarsky forest in 2012-2014 varied in the range of $20 \ldots 70 \mathrm{~cm}$, in 2012 and 2013 individuals with long shoots about $50 \mathrm{~cm}$ dominated, in 2014 with shoot length about 50 and $60 \mathrm{~cm}$. The feature of the shoot length is characterized by plasticity, the highest level of variation was observed in 2013. The lengths of shoots are inside the range specified for the various parts of the area in the literature with a significant proportion of "tall" plants in the studied population. This may be a sign of good growth conditions for Fritillaria ruthenica that gives an opportunity to the plant conservation in natural communities in the absence of limited anthropogenic factors.

Keywords: Fritillaria ruthenica Wikstr; morphological and bioecological features; quantitative and qualitative characteristics; shoot length; Krasnosamarsky forest; model biotope; Samara region.

\section{ОСОБЕННОСТИ ПИЩЕВОГО ПОВЕДЕНИЯ ЕНОТОВИДНОЙ СОБАКИ (NYCTEREUTES PROCYONOIDES GRAY, 1834) В ЗАВИСИМОСТИ ОТ ВЕЛИЧИНЫ СНЕЖНОГО ПОКРОВА} НА ПОЙМЕННОЙ ТЕРРИТОРИИ НАЦИОНАЛЬНОГО ПАРКА «САМАРСКАЯ ЛУКА» (C) 2016

В.В. Мартынова, аспирант кафедры экологии, ботаники и охраны природы Самарский национальный исследовательский университет имени академика С.П. Королёва, Самара (Россия)

Аннотащия. Енотовидная собака в пределах Самарской Луки является интродуцированным видом, отличается большой экологической пластичностью. Она успешно акклиматизировалась, и в настоящий момент продолжает расширять свой ареал. В этом аспекте особенно актуальным является изучение поведения вида. Важно отметить адаптацию вида в условиях антропогенной нагрузки, которая присутствует в условиях национального парка. Исследования проводилось на пойменных территориях национального парка Самарская Лука (с. Мордово и с. Малая Рязань), так как енотовидная собака тяготеет к пойменным участкам рек, островам и протокам, и сравнительно редко появляется на больших открытых пространствах. Объект исследования является популяция енотовидных собак пойменной территории национального парка. Был использован метод де- 